\title{
A modified medium that significantly improves the growth of human normal ovarian surface epithelial (OSE) cells in vitro
}

\author{
Ningfeng $\mathrm{F} \mathrm{Li}^{1}$, George Wilbanks ${ }^{1,2}$, Frances Balkwill ${ }^{1}$, Ian J Jacobs ${ }^{1}$, Dimitra Dafou ${ }^{1}$ \\ and Simon A Gayther ${ }^{1}$ \\ ${ }^{1}$ Cancer Research UK Translational Oncology Laboratory, Barts and The London, Queen Mary's Medical \\ School, Charterhouse Square, London, UK and ${ }^{2}$ Departments of Obstetrics and Gynecology and Pathology, \\ University of South Florida College of Medicine and H. Lee Moffitt Cancer Center, Tampa, FL, USA
}

\begin{abstract}
Approximately $90 \%$ of malignant ovarian tumours are epithelial and thought to arise from a single cell layer, the ovarian surface epithelium. In culture, human normal ovarian surface epithelial (OSE) cells have a very limited lifespan before they senesce, rarely progressing beyond 10 population doublings. This has restricted the use of normal OSE cells for studying the biology of ovarian surface epithelium and identifying molecular events that contribute to malignant transformation. We have investigated the conditions for culturing human, normal OSE cells in vitro using modified media. Culturing normal OSE cells in a modified medium (NOSE-CM) supplemented with epidermal growth factor, hydrocortisone, insulin and bovine pituitary extract led to significant improvements in the seeding and cloning efficiencies, overall cell growth and lifespan compared to culturing in a basic, nonsupplemented medium (BM) and previously used media (F-12 K medium and William's medium E). Cells cultured in NOSE-CM underwent, on an average, 19.0 population doublings (95\% Cl 16.3-21.7); cells cultured in BM underwent 0.43-3.52 population doublings over a similar time period. Growth curves established for different lines indicated that OSE cells continued to grow beyond passage 11 and up to passage 18 in NOSE$\mathrm{CM}$, but never beyond passage 7 when cultured in BM. It is likely that establishing optimal conditions for the growth of OSE cells in vitro will enable studies of the biological and genetic mechanisms of transformation in epithelial ovarian cancers.
\end{abstract}

Laboratory Investigation (2004) 84, 923-931, advance online publication, 12 April 2004; doi:10.1038/labinvest.3700093

Keywords: bovine pituitary extract; cloning efficiency; ovarian surface epithelium; population doubling; tissue culture

Ovarian cancer is the fifth most common cause of cancer-related death in women in developed countries; in the year 2000 alone, ovarian cancer was responsible for 114240 deaths worldwide, including 39145 deaths in Europe, 23759 in The Americas and 43555 in Asia (URL: http://www-dep.iarc.fr/ globocan/globocan.html). The lack of symptoms in early-stage disease often means that the disease is diagnosed at a late stage, resulting in poor overall 5-year survival. ${ }^{1,2}$

Most ovarian tumours are categorised as either epithelial, germ cell or sex cord tumours. Epithelial tumours, which are thought to arise from the ovarian surface epithelium (OSE), account for approxi-

Correspondence: Dr SA Gayther, Translational Oncology Laboratory, Barts and The London, Queen Mary's Medical School, Charterhouse Square, London EC1M 6BQ, UK.

E-mail: s.a.gayther@qmul.ac.uk

Received 4 December 2003; revised and accepted 11 February 2004; published online 12 April 2004 mately $60 \%$ of all ovarian tumours and $90 \%$ of malignant ovarian cancers. ${ }^{3}$ OSE is a single layer of flat/cuboidal epithelium that covers the surface of the ovary and has a mixed epithelio-mesenchymal phenotype. Epithelial features include keratin and mucin expression as well as the presence of desmosomes, apical microvilli and a basal lamina. Mesenchymal features include vimentin and $\mathrm{N}$ cadherin expression and an absence of the epithelial differentiation markers CA125 and E-cadherin. These mesenchymal features are apparent in normal oviductal and endometrial epithelium and also in ovarian carcinomas. ${ }^{4}$ This suggests that OSE may be the precursor tissue for ovarian epithelial malignancies. In support of this, multiple ovarian carcinoma cell lines have been shown to have epithelial characteristics. ${ }^{5,6}$ More recently, a mouse model for ovarian cancer has been developed by overexpressing oncogenes in mouse OSE resulting in phenotypic changes that are characteristic of cellular transformation. ${ }^{7}$ 
However, the biological and molecular mechanisms of ovarian epithelial carcinogenesis remain poorly understood. For example, the existence of a multistep transition from normal OSE to neoplastic epithelium, possibly involving a benign or borderline intermediate stage, has yet to be established. An in vitro cellular model of human ovarian epithelium may enable a greater understanding of the biology of normal OSE and possibly an understanding of the underlying molecular and biological events associated with the initiation and progression of ovarian epithelial malignancies.

A protocol for establishing primary human normal ovarian epithelial (NOSE) cells in vitro was first established by Auersperg et $a l^{8}$ in 1984. Since then, several other studies have reported successful culturing of primary NOSE cells..$^{9-12}$ However, these studies indicate that growth rates and the lifespan of NOSE cells from primary cultures are very limited and cell yields are variable between different samples. Cells rarely undergo more than 10 population doublings and frequently struggle to maintain their epithelial morphology when growth factors such as epidermal growth factor are used. ${ }^{8-10}$

Based on the experiences of previous studies, we have established a supplemented culture medium that significantly extends the lifespan and growth potential of human NOSE cells in vitro, while preserving their epithelial cell characteristics.

\section{Materials and methods}

\section{Primary Ovarian Surface Epithelial Cells and Primary Cell Culture}

Primary NOSE cells were obtained from the normal ovaries of women using a modification of the technique originally described by Kruk et $a .^{10}$ Samples were collected from 11 different cases (age range 28-54 years; mean age 44.8 years), of which five cases were postmenopausal and one case was undergoing hormone replacement therapy (Table 1). Patients underwent oophorectomy for several different reasons; three cases had been diagnosed with fibromyomata, four cases with stage I cervical squamous carcinoma, two cases with cervical intraepithelial neoplasia, one case with a benign ovarian cyst and one case because of a family history of ovarian/breast cancer. In all cases, specimens were taken from normal appearing ovarian surface epithelium, which was confirmed following histopathological review. Ethical committee approval (reference number T/02/035) was obtained for the collection of all samples.

Ovarian tissue specimens were removed either by laparotomy or laparoscopy. For laparotomy cases, the ovaries were gently elevated and brushed vigorously using a sterile plastic cervical cytology brush (Cytobrush ${ }^{\circledR}$ Plus GT, Medscand Medical AB, Sweden). Specimens were not taken from sites that suggested a recent ovulation. The brush was then agitated in $10 \mathrm{ml}$ of tissue culture medium (see below for details of media), centrifuged at $1500 \mathrm{~g}$ for $5 \mathrm{~min}$ before cell pellets were plated into $25 \mathrm{~cm}^{2}$ tissue culture flasks. Flasks were incubated at $37^{\circ} \mathrm{C}$ in 5\% $\mathrm{CO}_{2}$ without disturbance for 5-7 days to allow the cells to colonise. The medium was changed 2-3 times per week until cell confluence, after which cells were trypsinised and transferred to new tissue culture flasks using $0.025 \%$ trypsin $/ 0.01 \%$ versene in a ratio of 1:4.

For laparoscopic cases, affixing a sterile $0.1 \mathrm{~mm}$ diameter, 6 in long steel tube lengthened the

Table 1 Patient characteristics and growth properties of NOSE cells in different culture media

\begin{tabular}{|c|c|c|c|c|c|}
\hline \multirow[t]{2}{*}{ Patient no. } & \multirow[t]{2}{*}{ Age } & \multirow[t]{2}{*}{ Menopause stage } & \multirow[t]{2}{*}{ Cell line } & \multicolumn{2}{|c|}{ Culture days before reaching $80 \%$ confluence } \\
\hline & & & & MCDB105/199/15\%FCS (SB lines) & NOSE CM (NOSE lines) \\
\hline 1 & 28 & Premenopause & SB12L & 10 & - \\
\hline \multirow[t]{2}{*}{2} & 45 & Premenopause & SB14L & 13 & - \\
\hline & & & SB14R & 8 & - \\
\hline \multirow[t]{2}{*}{3} & 49 & Premenopause & SB16L & NG & - \\
\hline & & & SB16R & $40 \%$ confluence on day 16 & - \\
\hline \multirow[t]{2}{*}{4} & 50 & Postmenopause & SB19R & NG & - \\
\hline & & & NOSE19L & - & 5 \\
\hline 5 & 51 & Postmenopause & NOSE20 & - & 7 \\
\hline \multirow[t]{2}{*}{6} & 33 & Premenopause & SB21L & One clone on day 16 & - \\
\hline & & & NOSE21 & - & 10 \\
\hline \multirow[t]{2}{*}{7} & 54 & Postmenopause & SB24R & NG & - \\
\hline & & & NOSE24L & - & 9 \\
\hline \multirow[t]{2}{*}{8} & 54 & Postmenopause & SB25R & NG & - \\
\hline & & & NOSE25L & - & 7 \\
\hline \multirow[t]{2}{*}{9} & 41 & Premenopause & SB26L & 31 & - \\
\hline & & & NOSE26R & - & 8 \\
\hline \multirow[t]{2}{*}{10} & 54 & Postmenopause & SB27L & 29 & - \\
\hline & & & NOSE27R & - & 5 \\
\hline \multirow[t]{2}{*}{11} & 34 & Premenopause & SB29R & 18 & - \\
\hline & & & NOSE29L & - & 6 \\
\hline
\end{tabular}

NG: No growth in 21 days. 
cytology brush. The brush was carefully withdrawn through the trocar with the aperture open so as not to dislodge the cells. NOSE cells were then plated and cultured as described for laparoscopy cases.

\section{Media, Culture Reagents and Plastics}

We obtained MCDB105, Medium 199 with HEPES modification, insulin, hydrocortisone (HC), trypsin and versene from Sigma (St Louis, MO, USA), foetal bovine serum (FBS), human recombinant epidermal growth factor (EGF) and bovine pituitary extract (BPE) from Invitrogen (Paisley, Scotland, UK) and all tissue culture plastics from Becton Dickinson Labware (Franklin Lakes, NJ, USA). Serum batch tests were performed on Syrian hamster embryonic (SHE) cells obtained from Brunel University ( $R$ Newbold, personal gift) and on NOSE cells at passage 2 .

The compositions of the two primary media used in these studies are as follows: (1) MCDB105/199 (1:1); 15\% FBS (basic medium; BM); (2) MCDB105/ 199 (1:1); 15\% FBS; $10 \mathrm{ng} / \mathrm{ml}$ EGF; $0.5 \mu \mathrm{g} / \mathrm{ml} \mathrm{HC;}$ $5 \mu \mathrm{g} / \mathrm{ml}$ insulin; and $34 \mu \mathrm{g}$ protein/ml BPE (NOSE cell-supplemented complete medium; NOSE-CM). We also used two previously established culture media for comparative studies: nutrient mixture F-12 K Kaighn's modification and William's medium E (both from Invitrogen). Throughout the course of these experiments, cell lines were regularly tested and found to be negative for mycoplasma.

\section{Mass Culture Comparisons}

For mass culture comparisons in different media, we calculated the expansion of primary cells as the number of days culturing after primary plating in $25 \mathrm{~cm}^{2}$ flasks, before $80 \%$ confluence was reached. Growth curves were calculated as the population doubling (PD) times at each passage using the equation:

$$
\begin{gathered}
\mathrm{PD}=\lg (\text { total cell number at each passage } / \\
\text { initial cell number }) / \lg 2 .
\end{gathered}
$$

Cells were subcultured as follows: after primary cultures had expanded to $80 \%$ confluence, cells were transferred from $25 \mathrm{~cm}^{2}$ flasks into $80 \mathrm{~cm}^{2}$ flask (passage 1). When passage 1 cells reached $80 \%$ confluence, they were then passaged in a 1:3 ratio for culturing in $\mathrm{BM}$ and a 1:4/5 ratio for culturing in NOSE-CM depending on the growth potential of the cell line.

\section{Growth Curve Assays}

In all, $1 \times 10^{5}$ cells at passage 2 were plated into P60 dishes in triplicate. When $80 \%$ confluence was reached, cells were washed once with phosphatebuffered saline (PBS), trypsinised with $0.5 \mathrm{ml} 0.05 \%$ trypsin $/ 0.01 \%$ versene and counted using a haemocytometer. Cells were then split into either a 1:3 or 1:4 ratio for continued culturing. Total cell numbers and PDs were recorded as an average of the three platings. Cells that failed to reach $80 \%$ confluence within 1 month were defined as quiescent or senescent depending on the morphology, fixed in methanol and stained using crystal violet.

\section{Seeding and Cloning Efficiency}

We performed seeding and cloning efficiency assays on NOSE cells at passage 2 to assess short-term cell proliferation under different culture conditions, as follows: 100 cells were plated into P60 dishes in triplicate and cultured for 14 days; medium was changed twice, on days 5 and 10 . For cloning efficiency analysis, only clones comprising $\geq 10$ cells were recorded. For seeding efficiency assays, cells that attached without forming clones were considered attached cells. Seeding efficiency (SE) and cloning efficiency (CE) were calculated as follows:

$\mathrm{SE}_{i}=$ (number of attached cells + number of clones) $\times 100 \%$

$$
\begin{aligned}
& \overline{\mathrm{SE}}=\sum \mathrm{SE}_{i} / n, \quad S=\sqrt{\sum\left(\mathrm{SE}_{i}-\mathrm{SE}\right)^{2} /(n-1)}, \\
& \mathrm{CE}_{i}=\text { number of clones } \times 100 \%, \\
& \overline{\mathrm{CE}}=\sum \mathrm{CE}_{i} / n, \quad S=\sqrt{\sum\left(\mathrm{CE}_{i}-\mathrm{CE}\right)^{2} /(n-1)},
\end{aligned}
$$

where $\mathrm{SE}_{i}$ is the seeding efficiency of each P60 dish, $\mathrm{CE}_{i}$ the cloning efficiency of each P60 dish, $\overline{\mathrm{SE}}$ the average seeding efficiency, $\overline{\mathrm{CE}}$ the average cloning efficiency, and $N$ the replicate numbers of P60 dishes.

Levels of significance were calculated using $t$-tests, one-way ANOVA and Fisher's exact tests.

\section{Immunofluorescence Staining}

Pan-keratin (AE1/AE3, DAKO Corporation, Carpinteria, USA) and blood factor VIII (Stratech, Cambs, UK) were used as primary antibodies to verify the epithelial origin of cells. Cells were seeded on glass cover slips and cultured until $70-80 \%$ confluent. Cells were then washed twice in ice-cold PBS and fixed in $3 \%$ ice-cold formaldehyde. Half of all cover slips were permeabilised with $0.3 \%$ Triton X-100/ PBS to discriminate cell membrane nonspecific binding. Cells were incubated for $10 \mathrm{~min}$ in $1 \%$ nonimmune serum from the donor species of the secondary antibody to block nonspecific binding. Primary antibodies were diluted into different concentrations and cells incubated for $1 \mathrm{~h}$ at room temperature. After washing in PBS, cells were incubated in anti-mouse or anti-rabbit Alexa 488 secondary antibody (molecular probes) at room temperature for $30 \mathrm{~min}$. Vectashield mounting medium containing DAPI (Vector Lab, Burlingame, USA) 
was used to counterstain. Nonprimary antibody controls were incubated with the secondary antibody only to determine nonspecific binding. A human breast epithelial cell line (Bre-80) was used as a positive control for epithelial cell staining (Dafou et al, manuscript in preparation); a human primary skin fibroblast cell line (IBR) was used as a negative control for epithelial staining cell. Human endothelial cell line HUV-EC-C (ATCC, LGC Promochem, Middlesex, UK) was used as positive control for Factor VIII staining.

\section{Results}

\section{Effect of Supplementing Media on NOSE Cell Growth}

We tested the effect on NOSE cell growth of supplementing a basic culture medium with different growth factors. As a sensitive measurement of growth ability, we assessed the efficiency of single NOSE cells to seed and form clones comprising $\geq 10$ cells after 14 days of culturing. The BM was supplemented with epidermal growth factor (EGR), BPE, HC and insulin, individually and in combination. The most significant improvement in cloning efficiency was achieved by supplementing the BM with a combination of $34 \mu \mathrm{g}$ protein/ml BPE, $10 \mathrm{ng} /$ $\mathrm{ml} \quad$ EGF, $0.5 \mu \mathrm{g} / \mathrm{ml} \quad \mathrm{HC}$ and $5 \mu \mathrm{g} / \mathrm{ml}$ insulin $(P=0.0031)$ (Figure 1a); this was designated the optimal conditioned medium (NOSE-CM) in subsequent experiments.

We assessed cloning efficiencies in NOSE-CM for different NOSE cell lines established at passage 2. On average, $18.27 \%$ (95\% CI 13.34-23.20\%) of cells formed clones (Figure 1b). There was some variation in the appearance of clones from different lines. Clones from lines NOSE24L and NOSE27R appeared condensed, whereas clones from lines NOSE25L and NOSE26R appeared relatively dispersed (data not shown). Attempts to study the cloning efficiency of four cell lines established in BM alone were unsuccessful; in all cases, cells were either quiescent or underwent senescence after plating.

\section{Effect of Different Basic Media on NOSE Cell Growth}

The basic medium used to establish NOSE-CM comprised MCDB105 and Medium 199 (with HEPES

Figure 1 (a) Effect on the cloning efficiency of NOSE cells cultured in different compositions of basic and supplemented media. Cloning efficiencies are the average number of colonies formed for cell line NOSE21R after seeding 100 cells. Media compositions are as follows: (A) basic medium (BM); (B) $\mathrm{BM}+\mathrm{BPE}(34 \mu \mathrm{g}$ protein $/ \mathrm{ml}) ; \quad$ (C) $\mathrm{BM}+$ insulin $(5 \mu \mathrm{g} / \mathrm{ml}) ;$ (D) $\mathrm{BM}+\mathrm{HC} \quad(0.5 \mu \mathrm{g} / \mathrm{ml}) ; \quad$ (E) $\quad \mathrm{BM}+\mathrm{EGF} \quad(10 \mathrm{ng} / \mathrm{ml}) ; \quad(\mathrm{F})$ $\mathrm{BM}+\mathrm{EGF}+\mathrm{HC}+\mathrm{BPE}(P=0.027) ;(\mathrm{G}) \mathrm{BM}+\mathrm{EGF}+\mathrm{HC}+$ Insulin; (H) $\mathrm{BM}+\mathrm{EGF}+\mathrm{HC}$; and (I) NOSE-CM $(P=0.0031)$. (b) Cloning efficiency of five different NOSE cell lines (passage 2) cultured in NOSE-CM. (c) Effect of different basic media on the seeding and cloning efficiency of cell line NOSE 21R. All media contain the same supplements of EGF $(10 \mathrm{ng} / \mathrm{ml})$, HC $(0.5 \mu \mathrm{g} / \mathrm{ml})$, insulin $(5 \mu \mathrm{g} / \mathrm{ml})$ and BPE (34 $\mu \mathrm{g}$ protein/ml).
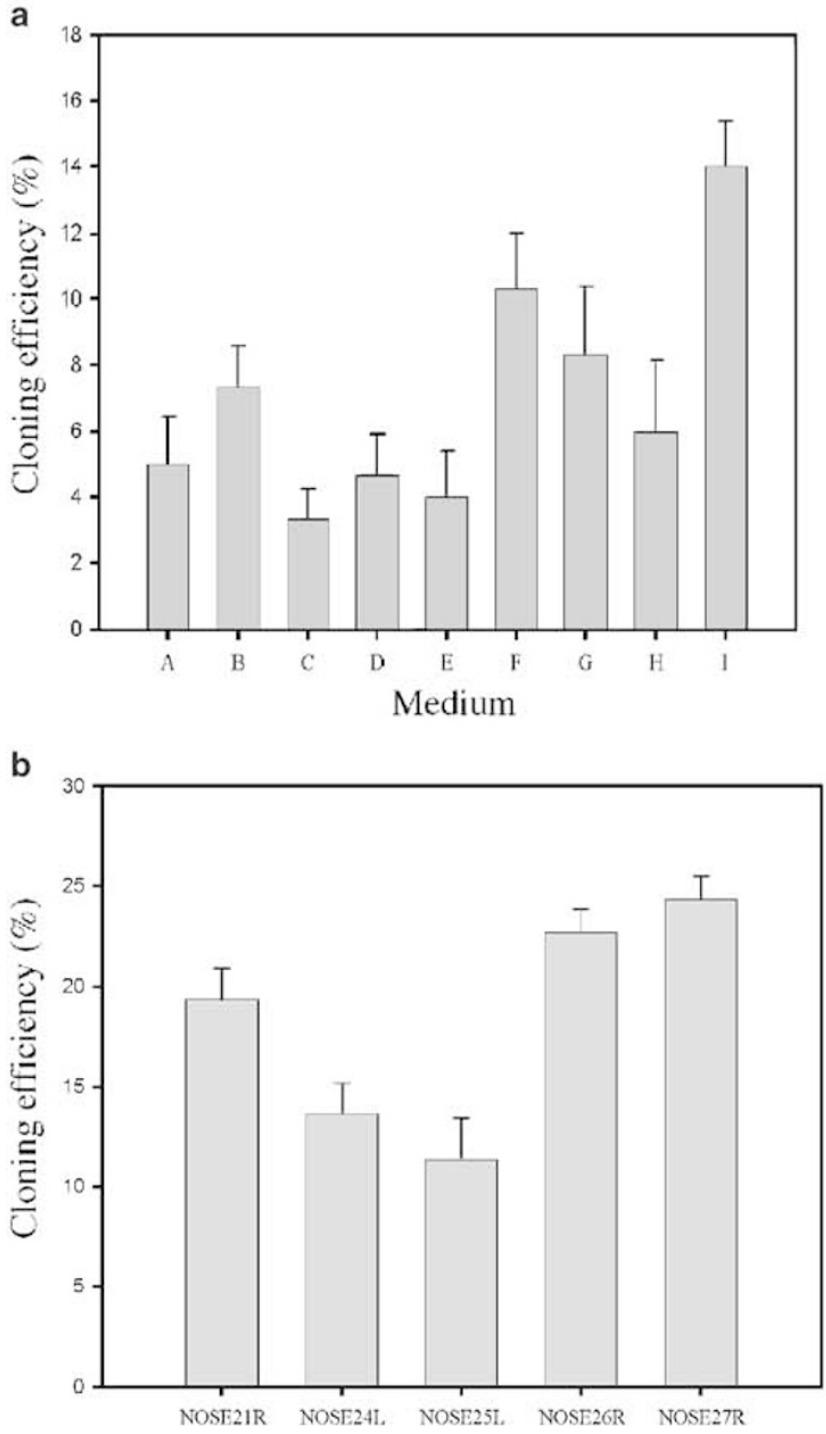

NOSE cell line

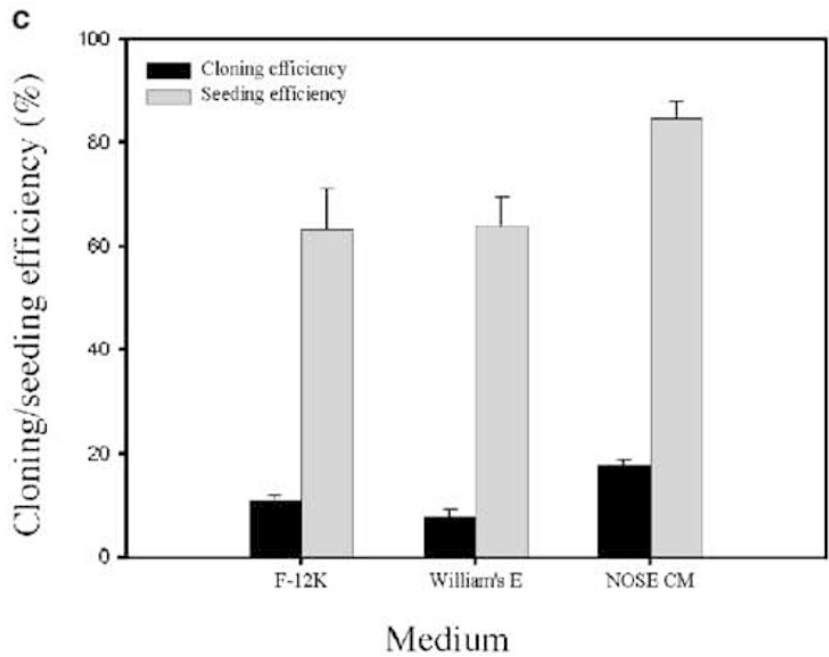


a

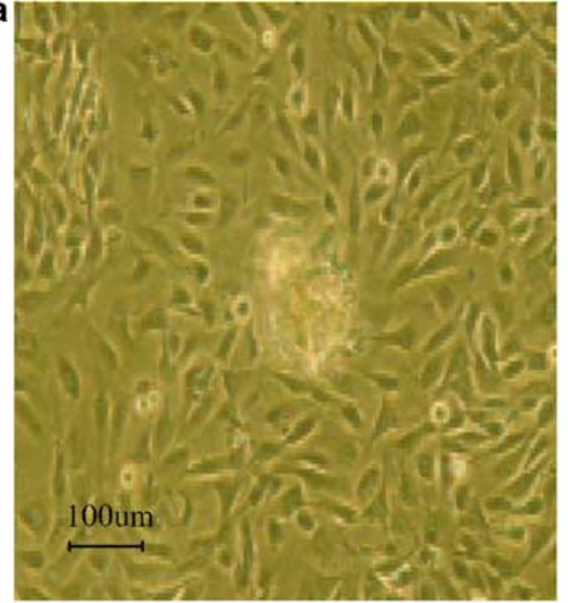

c

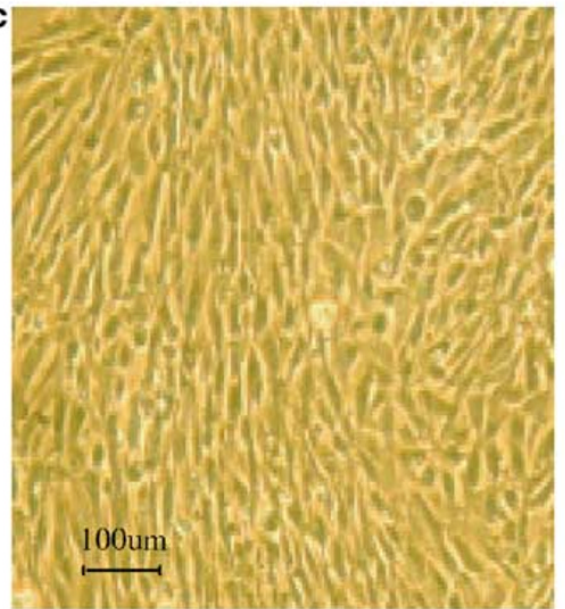

e

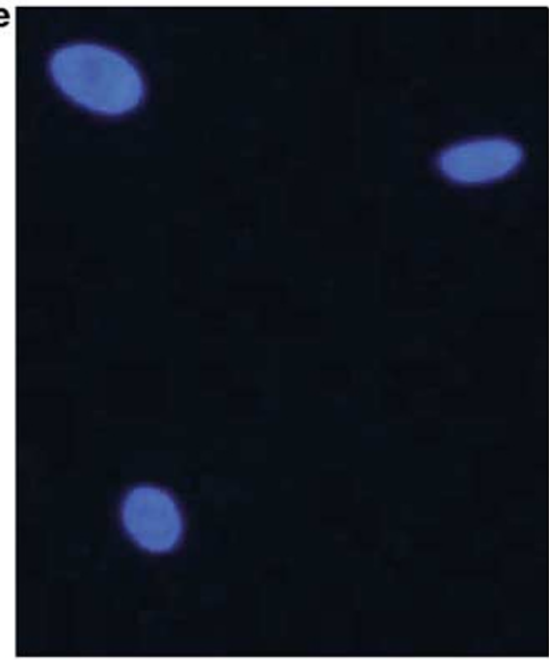

b

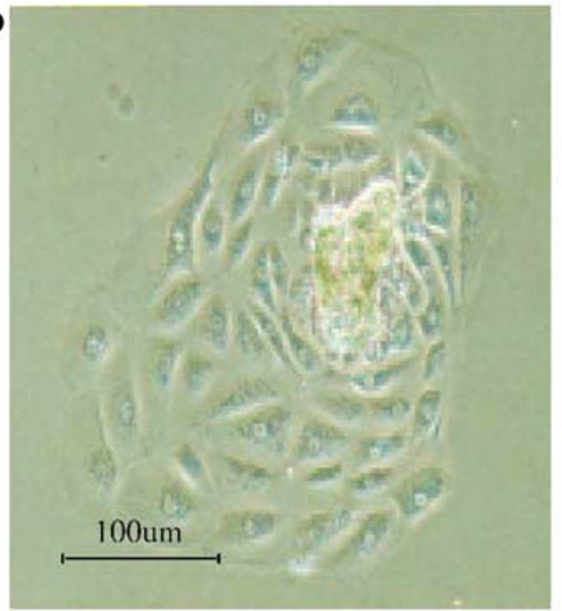

d
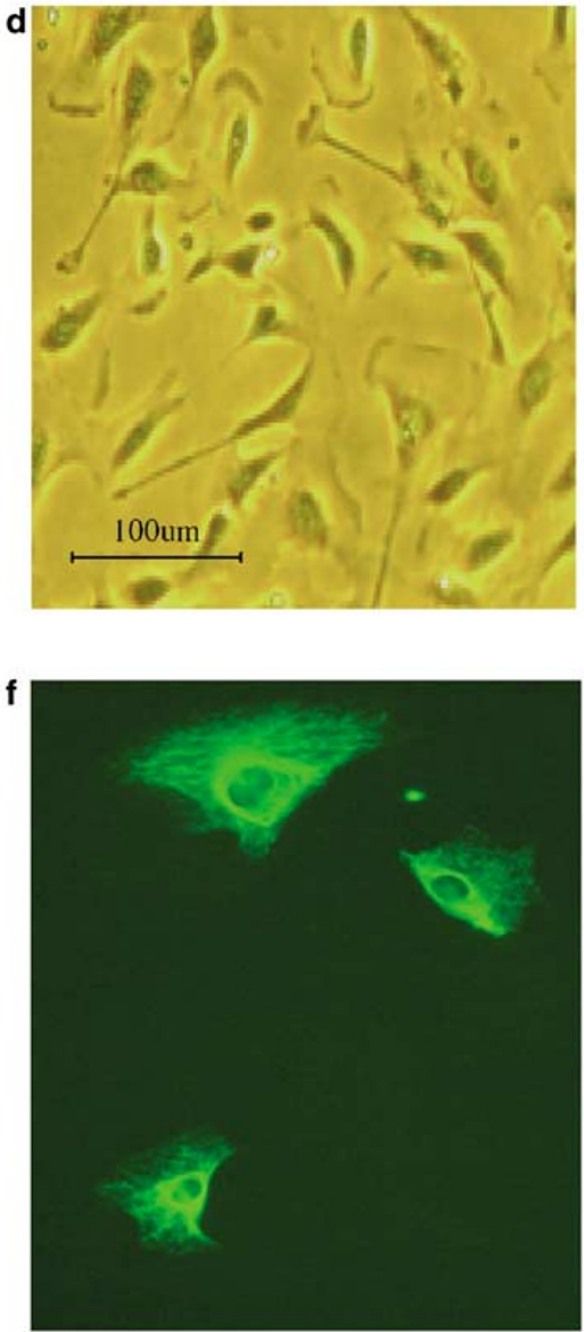

Figure 2 Morphology of normal ovarian surface epithelial (NOSE) cells: (a) primary cells cultured in NOSE-CM show a rapid outgrowth and colonise after $\sim 7$ days; clone size may reach $1-2 \mathrm{~mm}$ in diameter. Here, one clone is growing out of a small cell clump, magnification $\times 100$ phase contrast; (b) primary NOSE cells cultured in BM show a slow outgrowth compared to cells in NOSE-CM. Cells have a flatter, polygonal epithelial morphology, magnification $\times 200$ phase contrast; (c) NOSE cells cultured in NOSE-CM have 'spindleshaped' fusion cell morphology at high density, magnification $\times 100$, phase contrast; (d) at low density, NOSE cells cultured in NOSE-CM maintain a polygonal appearance with cytoplasm extension, magnification $\times 200$ phase contrast; (e) DAPI staining of NOSE cells, magnification $\times 200$. (f) Pan-keratin staining of NOSE cells, magnification $\times 200$. 


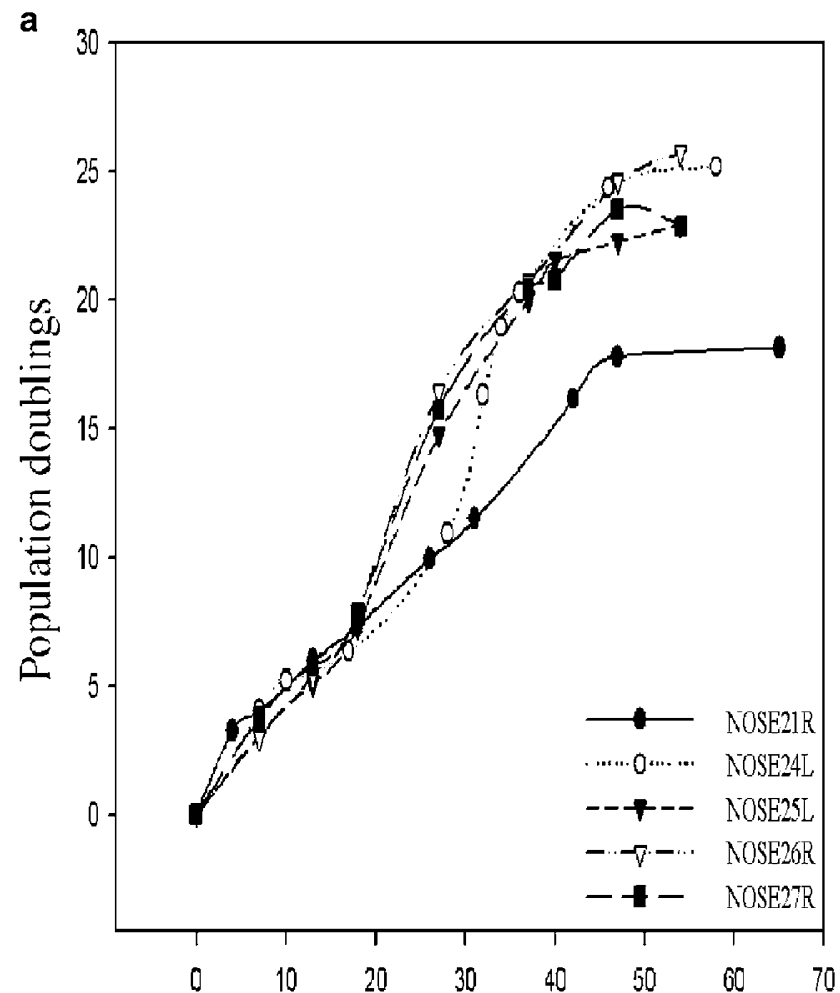

Days in culture

b

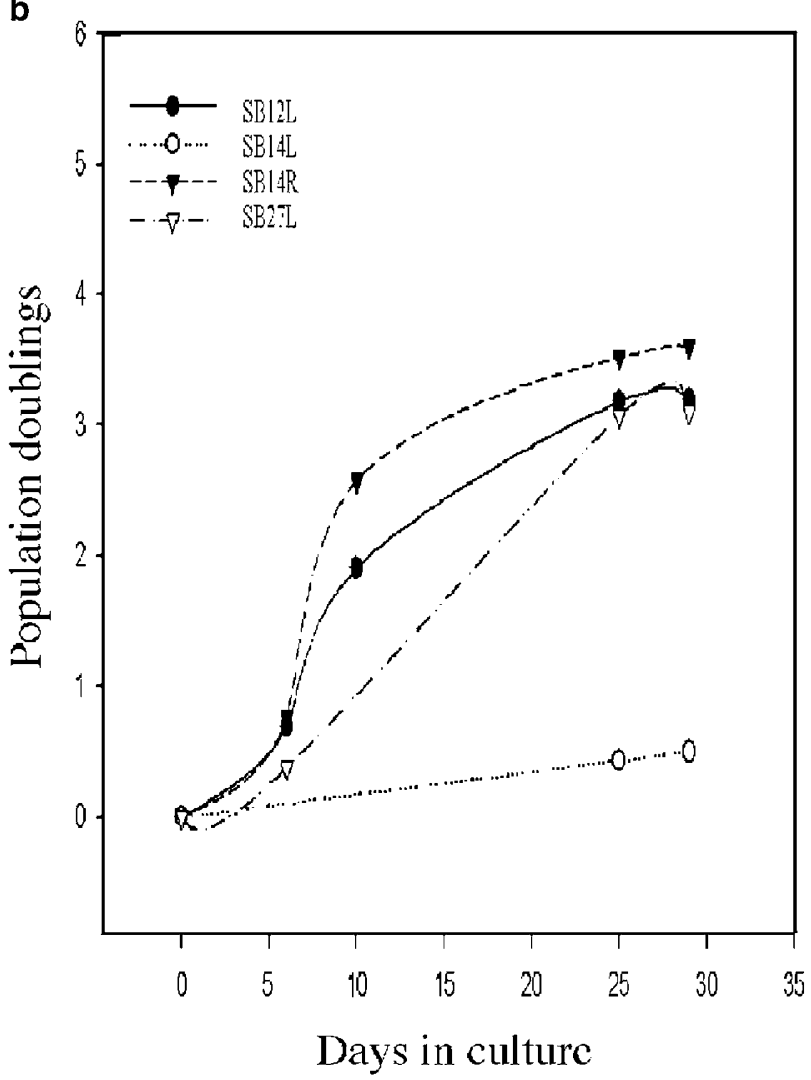

modification) in equal proportion. To assess whether different basic media can improve NOSE cell growth, we prepared F12-K and William's E media that were originally used for culturing ovarian epithelial cells. Both media were conditioned with the same growth factor supplements used in NOSE-CM.

We compared seeding and cloning efficiencies between the three media for the cell line NOSE21R. The seeding efficiency for this line in NOSE-CM was $84.67 \%$; seeding efficiencies were significantly less $(P<0.05)$ using conditioned $\mathrm{F}-12 \mathrm{~K}(63.33 \%)$ and William's E (64\%) media. The cloning efficiency of NOSE21R cells was also significantly better $(P<0.01)$ in NOSE-CM $(17.67 \%)$ compared to conditioned F-12 K (10.67\%) and William's E media $(7.67 \%)$ (Figure 1c).

\section{Establishing Primary NOSE Cells in Culture}

We compared the ability of primary NOSE cells to establish in culture in NOSE-CM and BM. We tested eight different primary cell lineages using NOSECM. All showed a consistent outgrowth 5-6 days after primary plating and reached $80 \%$ confluence in $25 \mathrm{~cm}^{2}$ flasks, on average, after 7.12 days (Table 1 ). The total cell yield at passage 1 was in excess of $5 \times 10^{5}$ cells in all cases with a minimum of 2-3 cell clumps plated initially. By contrast, NOSE cells struggled to establish themselves in BM alone and displayed a poor growth potential when they did (Figure 2a-b). Cells from six different cases took, on an average, 10 days to reach $80 \%$ confluence. A further six samples cultured in BM either failed to reach $80 \%$ confluence or showed no growth at all (Table 1). We observed no obvious correlation between patient age or menopausal status and the ability of primary NOSE cells to establish in different culture media, although sample numbers were small (Table 1).

\section{NOSE Cell Morphology and Growth Rates}

Cells cultured in BM exhibited a flat, simple epithelial morphology (Figure 2b). This is consistent with previous reports describing NOSE cells cultured in a basic medium. ${ }^{8-10}$ By comparison, cells cultured in NOSE-CM appeared smaller with an epithelial morphology at low density and were more spindle shaped with fusiform cells at high density (Figure 2c and d).

Figure 3 Growth curves for NOSE cells following subculture: (a) Growth curves for five NOSE cell lines cultured in NOSE-CM. Population doubling times were recorded after either passage 1 or 2 and until a state of quiescence was reached. (b) Growth curves for five NOSE cell lines cultured in BM. Compared to cells cultured in NOSE-CM, cells in BM show very slow growth and less than seven passages prior to quiescence or senescence. 


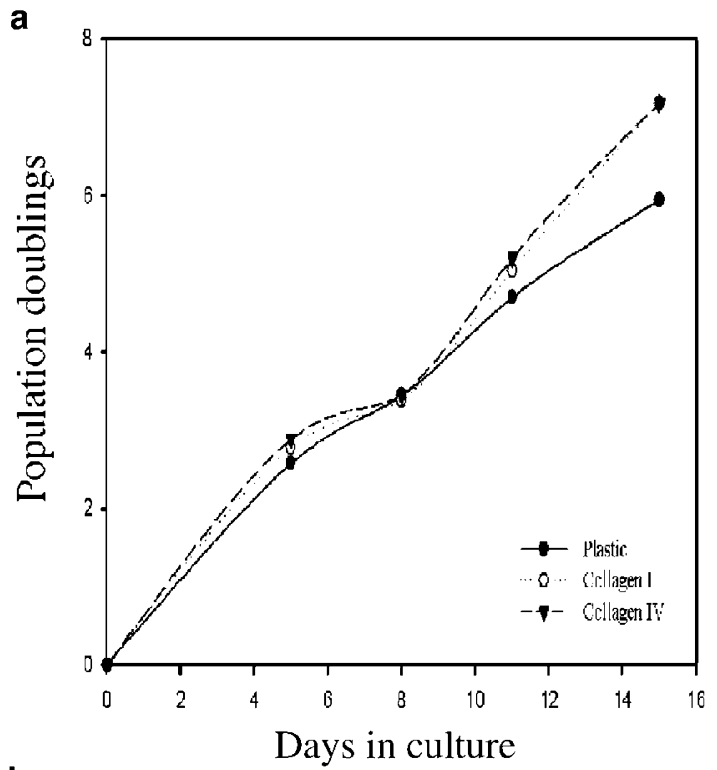

b
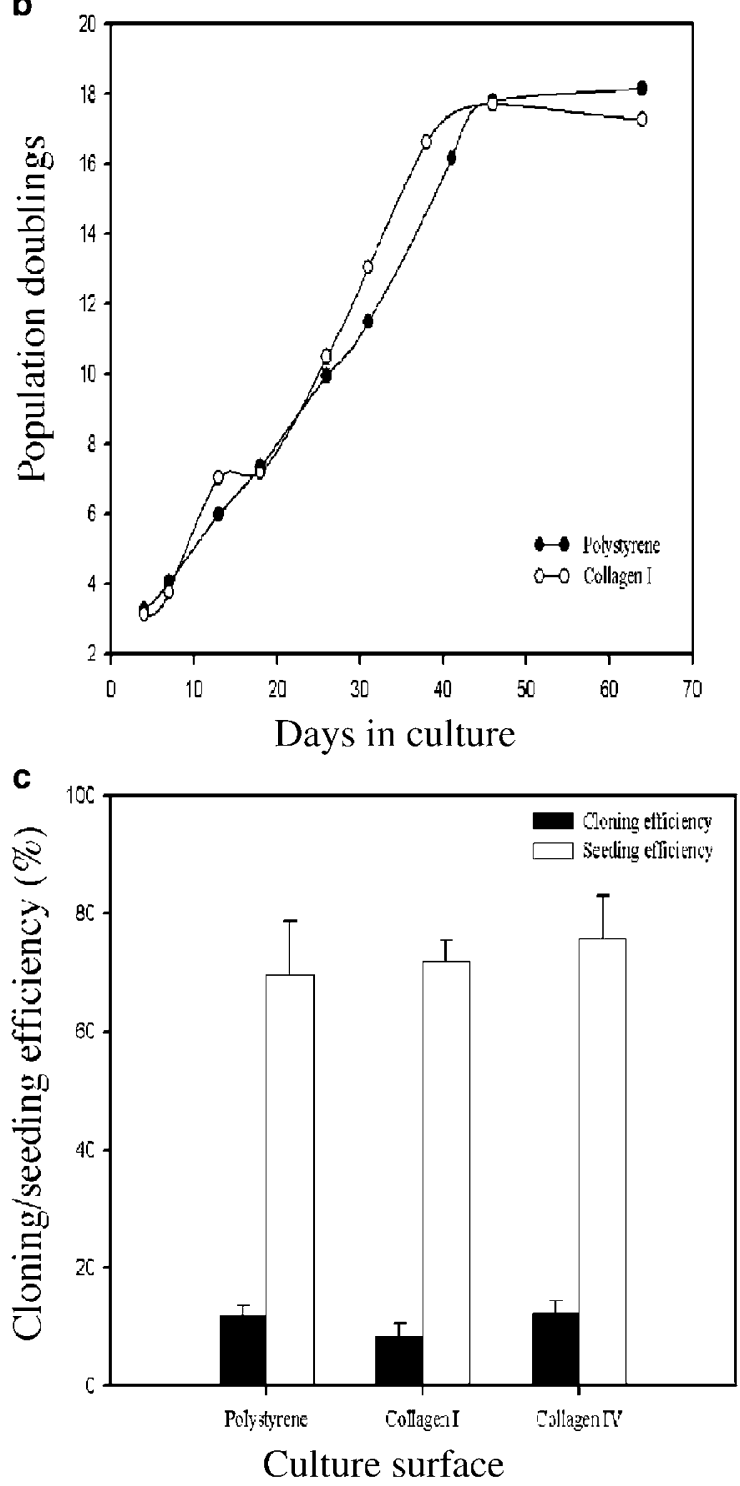

Figure 3 illustrates growth curves plotted for five different NOSE cell lines cultured in NOSE-CM (Figure 3a) and for four lines cultured in BM (Figure 3b). In NOSE-CM, cells continued to proliferate up to passage 11 in all cases and, in one case up to passage 18. By comparison, the lifespan of NOSE cells cultured in BM was shorter and in no cases did cell growth extend beyond passage 7 . There were also significant differences in PD times for cells cultured in different media (Figure 3). In NOSE-CM (Figure 3a), cells underwent one PD, on an average, every $48 \mathrm{~h}$ over the first 7 days. Typically, growth rates then slowed between days 7 and 15. There was then a more rapid and consistent growth up to about day 60 after which growth rates slowed significantly and a greater number of senescent/quiescent cells were observed. On an average, we recorded 19.0 PDs (95\% CI 16.3-21.7) over a 35-day period. By contrast, PDs for cells cultured in BM (Figure 3b) ranged from 0.43 to 3.52 over a 30 -day period. Cells did not proliferate measurably beyond 30 days.

\section{Effect of Collagen Coating on NOSE Cell Growth}

Collagen coating has been used for establishing NOSE cell lines. ${ }^{13,14}$ To assess the effect on NOSE cell growth of coating culture vessels, we cultured the lines NOSE 21R and NOSE24L on polystyrene-, collagen I- and collagen IV-coated surfaces (Figure 4). We observed no differences in seeding efficiency on different surfaces. However, we observed a slightly significant decrease in cloning efficiency on collagen I-coated compared to polystyrene- and collagen IV-coated surfaces $(P=0.045)$. Culturing on these three surfaces had little effect on overall cell growth or PD times over 30 and 60 days, respectively, although cells did appear to have a flatter and enlarged or elongated morphology on collagencoated surfaces.

\section{Epithelial Cell Characteristics of NOSE Cells}

Immunohistochemical staining with markers for cytokeratin and blood factor VIII was used to assess the cellular characteristics of NOSE cells established in culture. Consistent with their epithelial nature, cells stained positive for cytokeratin (Figure 2f) and

\footnotetext{
Figure 4 Growth of normal ovarian epithelial cells on collagen and noncollagen-coated surfaces: (a) short-term growth curves for line NOSE24L on collagen I-, collagen IV- and polystyrene-coated dishes indicate there are no differences in cell growth between the three surfaces; (b) long-term growth curves for line NOSE21R on collagen I and polystyrene dishes indicate that there are no differences in cell growth between the two surfaces; (c) cloning efficiencies of NOSE cells were significantly improved in collagen IV as compared to collagen I-coated surfaces $(P=0.04)$. There were no significant differences in seeding efficiencies on polystyrene- and collagen-coated surfaces.
} 
negative for blood factor VIII. We observed no differences in staining between cells cultured in BM and NOSE-CM. We also observed a decrease in the expression level of cytokeratin with increasing passage number, which is consistent with previous reports. $^{9,12}$ For line NOSE24L at passage $2,>80 \%$ of cells were positive for keratin staining. This had decreased to $5 \%$ by passage 9 .

\section{Discussion}

The ability to establish and maintain primary NOSE cells in culture is an essential requirement if the molecular genetic and biological properties of this cell type are to be studied in vitro. To some extent, this ability depends on the yield and quality of cells that can be collected; this has proved an impediment in the past due to the fragile and sparse nature of ovarian surface epithelium. In this study, we reduced the problems associated with the tissue collection by using a recently established 'brushing' method, which enabled us to collect sufficient numbers of epithelial cells without deep-layer, stromal cell contamination.

We found that supplementing a basic culture medium with a combination of growth factors (NOSE-CM) significantly improved the growth properties and lifespan of NOSE cells compared to the basic medium alone. Similar to previous studies, we tested the effects of adding EGF, HC and insulin, individually and in combination, to a basic medium $;{ }^{9}$ all combinations improved NOSE cell growth. Unlike other studies, we also used bovine pituitary extract (BPE) as a supplement, which resulted in further improvements in cell growth. Critically, there were no deleterious effects on the morphology and epithelial characteristics of NOSE cells when using NOSE-CM.

The biological rationale for an improvement in cell growth with the addition of EGF is well documented..$^{15-17}$ EGF, together with keratinocyte growth factor (KGF), hepatocyte growth factor (HGF) and tumour growth factor alpha (TGF- $\alpha$ ), stimulates OSE growth in vivo ${ }^{18,19}$ this is mediated through the EGF receptor, a transmembrane tyrosine kinase. ${ }^{20}$ However, in vitro, high concentrations of EGF can affect the morphology of NOSE cells resulting in a reversible conversion from a flattened epithelial appearance to a more spindle-shaped morphology. ${ }^{21}$ Reducing the EGF concentration in NOSE-CM to half of that reported previously had no apparent detrimental effect on the growth rates of NOSE cells; but cells cultured in lower levels of EGF were less spindle shaped and maintained a more flattened, cuboidal epithelial cell morphology.

We chose to supplement the culture medium with BPE because it is mitogenic and known to be rich in growth factors. BPE is commonly used as a supplement in serum-free media. ${ }^{22-24}$ Normal OSE expresses receptors for multiple growth factors present in BPE including oestrogen, progestin, luteinising hormone ( $\mathrm{LH})$, follicle stimulating hormone (FSH) and human chorionic gonadotrophin (hCG). ${ }^{25,26}$ Specific binding activity of hCG in NOSE cells has been shown to inhibit apoptosis via upregulation of insulin-like growth factor- $1 .{ }^{27}$ The presence of hCG in BPE may have led to reduced apoptosis, which could explain why BPE had such a positive effect on growth and in particular the cloning efficiency of NOSE cells. It will be necessary to grow NOSE cells in media conditioned with hCG alone to confirm this.

We were able to show that different basic media also had a significant effect on NOSE cell growth, which was independent of growth factor supplements. Past studies ${ }^{28,29}$ have shown that increasing levels of extracellular calcium can also stimulate NOSE cell growth; autocrine signalling triggered by an influx of calcium can activate protein kinase C and mitogen-activated protein (MAP) kinase, induce the oncogene Fos and phosphorylate focal adhesion kinase. Data also show that telomerase activation (which is known to extend cell lifespan) in ovarian epithelial cells is mediated by calcium. ${ }^{30}$ However, we found no improvement in NOSE cell growth when we used F-12 K medium (which contains a high concentration of calcium) compared to NOSE$\mathrm{CM}$ and William's E media (which contain lower calcium levels).

In conclusion, we have established a supplemented medium that significantly improves the growth potential and lifespan of normal ovarian epithelial cells in vitro. This is likely to have an important impact in the future on our ability to study the cellular and genetic mechanisms of transformation that result in ovarian epithelial cancer.

\section{References}

1 Goodman MT, Howe HL. Descriptive epidemiology of ovarian cancer in the United States, 1992-1997. North American Association of Central Cancer Registers. Cancer Suppl 2003;97:2615-2630.

2 Auersperg N, Ota T, Mitchell GWE. Early events in ovarian epithelial carcinogenesis: progress and problems in experimental approaches. Int J Gynecol Cancer 2002;12:691-703.

3 Chen VW, Ruiz B, Killeen JL, et al. Pathology and classification of ovarian tumors. Cancer Suppl 2003;97:2631-2642.

4 Wong AST, Auersperg N. Normal ovarian surface epithelium. Cancer Treat Res 2002;107:161-183.

5 Wilson AP, Dent M, Pejovic T, et al. Characterisation of seven human ovarian tumour cell lines. Br J Cancer 1996;74:722-727.

6 Hills CA, Kelland LR, Abel G. Biological properties of ten human ovarian carcinoma cell lines: calibration in vitro against four platinum complexes. Br J Cancer 1989;59:527-534.

7 Orsulic S, Li Y, Soslow RA, et al. Induction of ovarian cancer by defined multiple genetic changes in a mouse model system. Cancer Cell 2002;1:53-62. 
8 Auersperg N, Siemens CH, Myrdal SE. Human ovarian surface epithelium in primary culture. In Vitro 1984; 20:743-755.

9 Siemens CH, Auersperg N. Serial propagation of human ovarian surface epithelium in tissue culture. J Cell Physiol 1988;134:347-356.

10 Kruk PA, Maines-Bandiera SL, Auersperg N. A simplified method to culture human ovarian surface epithelium. Laboratory Invest 1990;63:132-136.

11 Dubeau L, Velicescu M, Sherrod AE, et al. Culture of human fetal ovarian epithelium in a chemicallydefined, serum-free medium: a model for ovarian carcinogenesis. Anticancer Res 1990;10:1233-1240.

12 Elliott WM, Auersperg N. Growth of normal human ovarian surface epithelial cells in reduced-serum and serum-free media. In Vitro Cell Dev Biol 1993;29A: 9-18.

13 Heino J. The collagen receptor integrins have distinct ligand recognition and signalling functions. Matrix Biol 2000;19:319-323.

14 Ohtake H, Katabuchi H, Matsuura K, et al. A novel in vitro experimental model for ovarian endometriosis: the three dimensional culture of human ovarian surface epithelial cells in collagen gels. Fertility Sterility 1999;71:50-55.

15 Huang HJS, Nagane M, Klingbiel CK, et al. The enhanced tumorigenic activity of a mutant epidermal growth factor receptor commom in human cancers is mediated by threshold levels of constitutive tyrosine phosphorylation and unattenuated signalling. J Biol Chem 1997;272:2927-2935.

16 Berchuck A, Rodriguez GC, Kamel A. Epidermal growth factor receptor expression in normal ovarian epithelium and ovarian cancer. Am J Obset Gynecol 1991;164:669-674.

17 Ottensmeier C, Swanson L, Strobel T, et al. Absence of constitutive EGF receptor activation in ovarian cancer cell lines. Br J Cancer 1996;74:446-452.

18 Havrilesky LJ, Hurteau JA, Whitaker RS. Regulation of apoptosis in normal and malignant ovarian epithelial cells by transforming growth factor beta. Cancer Res 1995;55:944-948.

19 Berchuck A, Rodriguez GC, Olt GJ, et al. Regulation of growth of normal ovarian epithelial cells and ovarian cancer cell lines by transforming growth factor-beta. Am J Obstet Gynecol 1992;166:676-684.
20 Heriksen R, Gobl A, Wilander E, et al. Expression and prognostic significance of TGF-beta isotypes, latent TGF-beta1 binding protein, TGF-beta type I and type II receptors and endoglin in normal ovary and ovarian neoplasms. Lab Invest 1995;73:213-220.

21 Auersperg N, Maines-Bandiera SL, Dyck HG, et al. Characterization of cultured human ovarian surface epithelial cells: phenotypic plasticity and premalignant change. Lab Invest 1994;71:510-518.

22 Kano-Sueoka T, Campbell GR, Gerber M. Growth stimulating activity in bovine pituitary extract specific for a rat mammary carcinoma cell line. J Cell Physiol 1977;93:417-424.

23 Holland MJ. The effect of bovine anterior pituitary extract on lipit mobilization in the rat and man. J Endocrinol 1969;44:307-311.

24 Wang HJ, Chen TM, Cheng LF, et al. Human keratinocyte culture using porcine pituitary extract in serumfree medium. Burns 1995;21:503-506.

25 Baldwin RL, Yamada SD, Bristow RE. Ovarian epithelial growth regulation. In: Sharp F, Blackett T, Berek J, Bast R (eds). Ovarian Cancer, 5th edn. Isis Medical Media: Oxford, 1998, p 99.

26 Brandenberger AW, Tee MK, Jaffe RB. Estrogen receptor alpha and beta mRNAs in normal ovary, ovarian serous cystadenocarcinoma and ovarian cancer cell lines: down-regulation of ER-beta in neoplastic tissues. J Clin Endocrinol Metab 1998;83: 1025-1028.

27 Kuroda H, Mandai M, Konishi I, et al. Human ovarian surface epithelial (OSE) cells express LH/HCG receptors, and HCG inhibits apoptosis of OSE cells via upregulation of Insulin-like growth factor-1. Int J Cancer 2001;92:309-315.

28 Rodland KD, Wersto RP, Hobson S, et al. Thapsigargininduced gene expression in nonexcitable cells is dependent on calcium influx. Mol Endocrinol 1997; 11:281-291.

29 Bast Jr RC, Mills GB. Molecular pathogenesis of ovarian cancer. In: Mendelsohn J, Howley PM, Isreal MA, Liotta LA (eds). The molecular basis of cancer. WD Saunders: The United States of America, 2001, pp 367-368.

30 Alfonson-de Matte MY, Moses-Soto H, Kruk PA. Calcium-mediated telomerase activation in ovarian epithelial cells. Arch Biochem Biophys 2002;399: 239-244. 